\title{
VALOR DA DOSAGEM DA TIREOGLOBULINA NO SEGUIMENTO DE PACIENTES COM CARCINOMA DIFERENCIADO DA TIREÓIDE SUBMETIDOS À TIREOIDECTOMIA PARCIAL
}

\author{
VALUE OF SERUM THYROGLOBULIN MEASUREMAT IN THE FOLLOW-UP \\ OF PATIENTS WITH DIFFERENTIATED CARCINOMA TREATED BY PARTIAL \\ THYROIDECTOMY
}

\author{
Aluízio Rodrigues, ECBC \\ Manuel Domingos da Cruz Gonçalves, TCBC-RJ ${ }^{2}$ \\ Marco Antonio Menezes Ferreira ${ }^{3}$ \\ José Gonçalves Veloso, ACBC-RJ ${ }^{4}$
}

\begin{abstract}
RESUMO: Objetivo: Estudar o valor da dosagem da tireoglobulina (Tg) plasmática na detecção de recidivas, nos pacientes com carcinoma diferenciado da tireóide, submetidos à tireoidectomia parcial. Métodos: São analisados, retrospectivamente, 48 pacientes portadores de carcinoma diferenciado e submetidos à tireoidectomia parcial que foram acompanhados no pós-operatório com dosagens de $\mathrm{Tg}$ plasmática. $\mathrm{O}$ exame foi realizado no paciente com TSH suprimido (<0,6mU/cc) e o valor da Tg de 10ng/cc considerado como limite entre os casos com e sem suspeita de recidiva. O tempo médio de seguimento foi de 8,1 anos. Resultados: Onze pacientes apresentaram Tg elevada (>10ng/cc) e quatro eram portadores de doença benigna capaz de elevar a Tg como hipertireoidismo (dois casos) e doença de Hashimoto (dois casos). Estes quatro pacientes não foram considerados na análise estatística. Os sete restantes foram considerados suspeitos de recidiva tumoral que foi confirmada em seis (verdadeiro positivo) e não confirmada em um (falso positivo). Nos 37 pacientes com Tg baixa (<10ng/cc) apenas um apresentou recidiva (verdadeiro negativo: 36 e falso negativo: 1). A análise estatística da capacidade da Tg em detectar recidivas mostrou: sensibilidade $85 \%$; especificidade $94 \%$; valor preditivo positivo $85 \%$; valor preditivo negativo $84 \%$ e acurácia 95\%. Conclusões: Os resultados obtidos neste trabalho mostraram que a dosagem da Tg é de valor na detecção de possibilidade de recidivas no seguimento de pacientes operados por carcinoma diferenciado mesmo quando submetidos à cirurgia parcial.
\end{abstract}

Descritores: Tireoglobulina; Carcinoma diferenciado; Tireoidectomia parcial.

\section{INTRODUÇÃO}

O valor da dosagem da tireoglobulina (Tg) plasmática para detectar recidivas no acompanhamento de pacientes submetidos à tireoidectomia parcial por carcinoma diferenciado é controvertido. Vários autores consideram indispensável a tireoidectomia total para valorizar o exame, argumentando que a persistência de tecido tireoidiano nas ressecções parciais pode ser os responsável por eventual elevação da Tg plasmática, mesmo na ausência de recidivas $^{1-6}$. Outros autores, contudo, valorizam o método mesmo sem tireoidectomia total, desde que realizado após supressão do TSH hipofisário pela administração prévia de hormônio tireoidiano ${ }^{7,8}$.

Neste trabalho, apresentamos nossa experiência com a dosagem da Tg no seguimento pós-operatório de pacientes submetidos à tireoidectomia parcial no tratamento do carcinoma diferenciado no Serviço de Cirurgia Geral do Hospital Universitário Clementino Fraga Filho.

\section{MÉTODOS}

Foram analisados 48 pacientes submetidos à tireoidectomia parcial e acompanhados com dosagens da $\mathrm{Tg}$

1. Professor Adjunto do Departamento de Cirurgia da Faculdade de Medicina da UFRJ.

2. Professor Adjunto do Departamento de Cirurgia da Faculdade de Medicina da UFRJ.

3. Professor Adjunto do Departamento de Cirurgia da Faculdade de Medicina da UFRJ.

4. Professor Adjunto do Departamento de Cirurgia da Faculdade de Medicina da UFRJ.

Recebido em 25/06/2001

Aceito para publicação em 08/10/2001

Trabalho realizado no Hospital Universitário Clementino Fraga Filho da UFRJ. 
plasmática estando o TSH suprimido. Não foram incluídos pacientes operados há menos de um ano, os que receberam no pós-operatório imediato doses ablativas de $\mathrm{I}^{131}$ e os com seguimento incompleto.

$\mathrm{Na}$ revisão dos prontuários foram anotados tipo e data da operação, patologia do tumor, dosagens da Tg e do $\mathrm{TSH}$, presença ou não de recidivas, data e estado do paciente na última revisão.

A presença da tireóide remanescente foi avaliada pela descrição da operação e confirmada pelas captações do $\mathrm{I}^{131}$ no pescoço e/ou cintigrafia pós-operatórias.

O método utilizado para a dosagem da Tg foi o RIA até junho de 1998, quando foi substituído pela quimioluminescência (ICMA) que é o método utilizado até hoje.

$\mathrm{O}$ exame foi realizado pela primeira vez uma a dois meses após a operação e depois, cada seis a 12 meses. Nos casos mais antigos, operados quando ainda não dispúnhamos da dosagem da Tg, o primeiro exame só foi realizado alguns anos após a cirurgia.

Todos os pacientes fizeram uso de T4 no pós-operatório sendo a dose ajustada para manter o TSH abaixo de $0,6 \mathrm{mU} / \mathrm{cc}$, ocasião em que foram feitas as dosagens da $\mathrm{Tg}$.

$\mathrm{O}$ valor de $10 \mathrm{ng} / \mathrm{cc}$ para a Tg plasmática foi estabelecido como limite entre possibilidade ou não de recidiva tumoral, conforme preconizado pela maioria dos trabalhos que abordam o assunto $5,7,8,9,10,15$.

Foram considerados suspeitos de apresentar recidivas os pacientes com três dosagens consecutivas acima daquele valor. Nos casos limítrofes e naqueles com Tg acima de 10ng/cc sem evidência clínica de recidivas, um ou mais dos seguintes exames foram utilizados: RX de tórax, US cervical, dosagem da Tg com TSH liberado, e captação de corpo inteiro (PCI) com dose elevada de $\mathrm{I}^{131}(100 \mathrm{mCi})^{4,5}$.

Foram considerados como verdadeiro positivo (VP) os casos com Tg elevado e recidiva confirmada; falso positivo (FP) aqueles com Tg elevado e recidiva não confirmada; verdadeiro negativo (VN) com Tg baixa em que nenhuma recidiva foi encontrada e falso negativo (FN) quando a $\mathrm{Tg}$ foi baixa mas confirmou-se presença de recidiva.

A sensibilidade $(\mathrm{VP} / \mathrm{VP}+\mathrm{FN})$, a especificidade $(\mathrm{VN} / \mathrm{VN}+\mathrm{FP})$, o valor preditivo positivo $(\mathrm{VP} / \mathrm{VP}+\mathrm{FP})$, o valor preditivo negativo (VN/VN $+\mathrm{FN})$ e a acurácia $(\mathrm{VP}+\mathrm{VN} / \mathrm{VP}+\mathrm{VN}+\mathrm{FN})$ foram então calculados.

\section{RESULTADOS}

As cirurgias realizadas nos 48 pacientes estudados foram: lobectomia subtotal (um caso), lobectomia total + istmectomia (28 casos), lobectomia total + lobectomia subtotal no lado oposto (13 casos) e tireoidectomia subtotal (seis casos).

A variedade do carcinoma foi papilífero em 28 casos e folicular em 20 .

O tempo médio de seguimento foi de 8,1 anos (extremos um e 21 anos).

Onze pacientes apresentaram Tg acima de 10ng/cc (com TSH suprimido) em pelo menos três amostras su- cessivas: seis foram reoperados e confirmada presença de recidiva; um outro paciente, com Tg acima de $3.000 \mathrm{ng} / \mathrm{cc}$, recusou-se a prosseguir na investigação da provável recidiva. Nos quatro restantes, dois apresentavam recidiva de hipertireoidismo e foram tratados com $\mathrm{I}^{131}$, normalizando-se a Tg meses após. Os dois outros pacientes apresentavam anticorpos antitireoglobulina elevados no plasma, o que sabidamente falseia o resultado da dosagem da tireoglobulina. Ambos eram portadores de tireoidite de Hashimoto associada ao carcinoma e confirmados na primeira operação. Um deles foi reoperado por apresentar recidiva de nódulo no lobo remanescente e a patologia revelou apenas tireoidite; o outro continua em observação sem apresentar nenhuma evidência de recidiva tumoral. Estes quatro pacientes foram excluídos da análise estatística.

Resumindo, dos 11 pacientes com Tg elevada, em quatro esta elevação foi causada por lesões benignas no lobo remanescente, facilmente diagnosticadas e afastada recidiva tumoral. Nos sete casos restantes, a suspeita de recidiva foi confirmada em seis através de nova cirurgia (verdadeiro positivo: seis ou $85,7 \%$ ) e em apenas um, que recusou prosseguir na pesquisa, não pôde ser confirmada a provável recidiva (falso positivo: um ou 14,2\%).

Nos 37 pacientes com Tg baixa em apenas um confirmou-se recidiva, em linfonodo cervical (falso negativo: um ou $2,7 \%$ ). Nos 36 restantes, não ocorreram recidivas até a última revisão num seguimento médio de 7,4 anos com extremos de um e 21 anos (verdadeiro positivo: 36 ou $97,3 \%$ ).

No presente estudo a dosagem da Tg na detecção de recidiva tumoral mostra: sensibilidade $85 \%$, especificidade $94 \%$, valor preditivo positivo $85 \%$, valor preditivo negativo $94 \%$ e acurácia $95 \%$.

Após a ressecção da recidiva, dos cinco pacientes com doença locorregional quatro tiveram o valor da $\mathrm{Tg}$ plasmática reduzido a níveis inferiores a 10ng/cc e apenas um permaneceu com níveis elevados, embora clinicamente sem evidência da doença. Nos pacientes com metástases a distância, a Tg permanece elevada apesar da totalização da tireoidectomia e do emprego do I ${ }^{131} \mathrm{em}$ doses terapêuticas. Cumpre salientar que nestes dois pacientes que apresentavam também recidiva na glândula residual, os níveis elevados da Tg já haviam sido detectadas dois e três anos, respectivamente, antes de as metástases serem identificadas clinicamente.

\section{DISCUSSÃO}

A tireoglobulina é uma glicoproteína unicamente produzida pelas células tireoidianas normais ou patológicas. Após tireoidectomia total a Tg plasmática baixa a níveis não mensuráveis pelos métodos de dosagens conhecidos. Desta forma, quando esta cirurgia é realizada para tratamento do carcinoma diferenciado, a detecção de Tg no plasma dos pacientes no pós-operatório sugere fortemente persistência ou recorrência do tumor e por isso o 
seu uso tornou-se rotineiro no acompanhamento destes pacientes.

Com base nestes conhecimentos, vários autores consideram indispensável a tireoidectomia total em todos os portadores de carcinoma diferenciado, a fim de despistar recidivas com a dosagem da $\mathrm{Tg}$ plasmática no pós-operatório ${ }^{1-6}$.

A produção da $\mathrm{Tg}$, assim como a dos hormônios tireoidianos $\left(\mathrm{T}_{3}\right.$ e $\left.\mathrm{T}_{4}\right)$, é dependente do $\mathrm{TSH}$ hipofisário. Entretanto, nas hiperplasias e nas neoplasias da glândula, esta dependência é relativa e a produção da Tg nestas situações é, em grande parte, autônoma ${ }^{11,12}$.

A experiência tem mostrado que, como a produção de Tg pelo tecido tireoidiano é dependente do TSH hipofisário, a inibição deste hormônio com a administração de hormônios tireoidianos no pós-operatório reduz a produção da Tg pela tireóide remanescente a níveis muito baixos. Nesta situação, um aumento da Tg a valores superiores a 10ng/cc alerta para a possibilidade de recidiva, que é capaz de produzir Tg independente do TSH ${ }^{11}$.

Algumas patologias, contudo, que ocorram no tecido tireoidiano remanescente e que, da mesma forma que as recidivas, produzam $\mathrm{Tg}$ independente do $\mathrm{TSH}$ como doença de Graves, nódulos hiperplásicos e tireoidite de Hashimoto ${ }^{11,12}$, podem elevar a Tg de níveis acima de 10ng/cc. Estas patologias, contudo, são facilmente diagnosticadas pela clínica e ou pela punçãobiopsia com agulha fina (em casos de nódulos palpáveis) e desta forma descarta recidiva como causa de hipertireoglobulinemia.

Isso ocorreu em quatro dos nossos casos que apresentaram Tg elevada no seguimento pós-operatório: dois com recidiva de hipertiroidismo e dois com doença de Hashimoto. Dos quatro, três foram tratados sem reoperação e estão atualmente com Tg baixa. Apenas um foi operado devido ao crescimento de nódulo no lobo remanescente e a patologia confirmou tireoidite de Hashimoto. Como são patologias facilmente diagnosticadas, não constituem limitação ao controle pós-operatório com a dosagem da Tg.

Vale também lembrar que a elevação da $\mathrm{Tg}$, nas recidivas tumorais é quase sempre constante e progressiva, quando o exame é realizado com TSH suprimido e em níveis semelhantes ${ }^{14}$, fato este não verificado nos nossos quatro casos de "falsos positivos", nos quais os valores da $\mathrm{Tg}$, embora mantidas elevados, foram oscilantes.

Nos outros sete casos desta série com Tg acima de $10 \mathrm{ng} / \mathrm{cc}$, seis apresentaram recidiva tumoral. É interessante ressaltar que a média dos valores encontrados para o Tg foi bem maior nas metástases a distância $(119,8 \mathrm{ng} / \mathrm{cc})$ que nas recidivas locorregionais $(40,2 \mathrm{ng} / \mathrm{cc})$, fato este também encontrado por outros autores $2,9,13$.
Assim, dos 48 pacientes estudados em 11 a Tg plasmática se encontrava elevada (> $10 \mathrm{ng} / \mathrm{cc}$ ) e, excluindo os quatro casos cuja elevação foi motivada por lesões benignas que puderam ser facilmente diagnosticadas, dos sete restantes, seis apresentavam recidivas, perfazendo $85,7 \%$ de verdadeiro positivo e de $4,5 \%$ (um de sete casos) de falso positivo, com a dosagem da Tg pós-tireoidectomia parcial.

Nos 37 casos com Tg igual ou menor que 10ng/cc em apenas um confirmou-se recidiva tumoral dando um percentual de $2,7 \%$ de falso negativo. Tratava-se neste caso de metástase para um linfonodo cervical que foi palpado clinicamente e surgido 14 anos após a primeira cirurgia. Cumpre salientar que as dosagens da $\mathrm{Tg}$ neste caso vinham se elevando nos últimos anos e as duas últimas foram de $9 \mathrm{ng} / \mathrm{cc}$. Como referem alguns autores $^{5,6}$, a recidiva em linfonodos, quando pequena, pode não elevar a Tg mas é quase sempre identificada pela palpação ou pelo US cervical, que deve ser sempre solicitado nos valores limítrofes da Tg; além de serem facilmente ressecadas as metástases em linfonodos cervicais não comprometem a sobrevida do paciente. Os 36 casos restantes (com Tg menor que 10ng/cc) não apresentaram, até a última revisão, recidiva do tumor, o que confere ao método $97,3 \%$ de verdadeiro negativo. A análise estatística desta nossa experiência forneceu dados que comprovam a sua validade: sensibilidade de $85 \%$, especificidade de $94 \%$, valor preditivo (+) de $85 \%$, valor preditivo (-) de $94 \%$ e acurácia de $95 \%$. Estes dados são semelhantes aos relatados por Harvey et al. ${ }^{8}$ que comparam valores da Tg após tireoidectomia parcial com os encontrados após tireoidectomia total e concluíram que são semelhantes: sensibilidade de $92 \%$ e especificidade de $100 \%$ com a cirurgia parcial, e $86 \%$ e $100 \%$ com a cirurgia radical, respectivamente. De Vathaiare et al. ${ }^{7}$ também referem resultados semelhantes. Cumpre salientar que Schlamberger et al. ${ }^{6}$ referem resultados superiores com a tireoidectomia total: sensibilidade de $98 \%$ e especificidade de $100 \%$; com a tireoidectomia parcial a sensibilidade foi de $49 \%$ e a especificidade de $97,5 \%$. Contudo, neste trabalho ${ }^{6}$, os autores estabeleceram o limite mínimo do valor da Tg em 29ng/cc, para considerar suspeita de recidiva e, desta forma, os pacientes com valores da Tg plasmática entre $10 \mathrm{ng} / \mathrm{cc}$ e $29 \mathrm{ng} / \mathrm{cc}$ não foram incluídos entre os suspeitos, o que explica a baixa sensibilidade encontrada após tireoidectomia parcial.

Os resultados por nós obtidos na revisão destes 48 pacientes mostram que a dosagem da Tg plasmática é de grande valor para alertar sobre a possibilidade de recidivas do carcinoma diferenciado submetidos à tireoidectomia parcial, indicando pesquisa mais minuciosa neste grupo de pacientes, ao mesmo tempo que afasta a necessidade desta pesquisa quando o valor da Tg encontrado é baixo. 


\begin{abstract}
Background: Serum thyroglobulin determination has been reported to be a sensitive indicator of recurrent differentiated thyroid carcinoma. The purpose of this study is to determine the accuracy of serum thyroglobulin levels in predicting tumor recurrency after parcial thyroidectomy. Methods: Forty eight patients with differentiated thyroid carcinoma were followed with serum thyroglobulin measurement after parcial thyroidectomy. Patiens recived hormonal suppressive therapy to maintain plasma TSH level below 0,6 mU/cc. Mean follow-up was 8,1 years. Serum thyroglobulin level above 10ng/cc was considered suspect of tumor recurrency. Results: Eleven patients showed serum thyroglobulin level above $10 \mathrm{ng} / \mathrm{cc}$. In four of them, elevations were considered spurious (hiparthyroidisme - 2 cases, and Hashimoto disease - 2 cases) and were excluded from statistical analysis. In the other 7, tumor recurrence was demonstrated in 6 (true positive: 6; false positive: 1). In 37 patients with low thyroglobulin level, only 1 had recurrence (true negative: 36; false negative: 1). Statistical analysis show sensibility $85 \%$, specificity $94 \%$, positive predictive value $85 \%$, negative predictive value $84 \%$ and accuracy $95 \%$. Conclusions: Serum thyroglobulin determination is an useful test to identify patients with persistent or recurrent differenctiated cancer, inicially submited to parcial thyroidectomy.
\end{abstract}

Key Words: Thyroglobulin; Differentiated carcinoma; Parcial thyroidectomy.

\title{
REFERÊNCIAS
}

1. Van Herle AJ, Vassart G, Dumont E. Control of Thyroglobuliny Synthesis and secretion (second of two parts), N. Engl. J. Med., 1979; 6:307-14.

2. Duren N, Siperstein AF, Shen W et al. Value of stimulated serum thyroglobulin levels for detecting persistent or recurrent differentiated thyroid cancer in high-and low-risk patients. Surgery, 1999; 126:13-9.

3. Le Gerfo P, Colacchio T, Colacchio D et al. Thyroglobulin in benign and malignant thyroid discase. JAMA, 1979; 241:923-5.

4. Spencer CA, Wang C. Thyroglobulin measurement. Techniques, clínical benefits and pitfalls. End. Met. $\mathrm{Cl}$. North Am., 1995; 24:841-63.

5. Schlumberger M, Baudin E. Serum thyroglobulin determination in the follow-up of patients with differentiated thyroid carcinoma. Eur. J. Endoc. 1998; 138:249-52.

6. Schlumberger M, Fragu P, Parmentier C et al. Thyroglobulin assay in the follow-up of patients with differentiated carcinomas: comparision of its value in patients with or without normal residual tissue. Acta Endocr. 1981; 98:215-21.

7. De Vathaire F, Blanchon S, Schlamberger M. Thyroglobulin level helps to predict recurrence after lobo-isthmusectoy in patients with differentiated thyroid carcinoma. Lancet, 1988; 1:52-3.

8. Harvey RD, Matheson NA, Grabowski PS et al. Measurement of serum thyroglobulin is of value in detecting tumor recurrence following treatment of differentiated thyroid carcinoma by lobectomy. Brit. J. Surg., 1990; 77:324-6.

9. Schlumberger M, Arcangioli O, Pickarski JD et al. Detection and treatment of lung metastases of differentiated thyroid carcinoma in patients with normal chest $\mathrm{x}$ rays. J. Nucl. Medicine, 1988; 29:1790-4.

10. Schlumberger M, Tubiana M, De Vathaire F et al. LongTerm results of treatment of 283 patients with lung and bone metastases from differentiated thyroid carcinoma. J. Clin. Endoc. Metab. 1986; 63:960-7.
11. Refetoff $S$, Lever EG. The value of serum thyroglobulin measurement in clinical practice. JAMA, 1983; 250:23527.

12. Morita T, Tamai H, Ohshima A et al. Changes in serum thyroid harmone. Thyrotropin and thyroglobulin concentrations during thyroxe therapy in patients with solitary thyroid nodules. J. Clin. Endoc. Met. 1989; 69:227-30.

13. Shah DH, Dandekar SR, Juvansam RK et al. Serum thyroglobulin in differentiated thyroid carcinoma: histological and metastatic classification. Acta Endoc. 1981; 98: 222-6.

14. Schlumberger $\mathrm{M}$, Charbord $\mathrm{P}$, Fragu $\mathrm{P}$ et al. Circulating thyroglobulin and thyroid hormones in patients with metastases of differentiated thyroid carcinoma: relation to serum thyrotropin levels. J. Clin. Endoc. Metabol., 1980; 51:513-19.

15. Schneider AB, Line BR, Goldman JM. Sequential serum thyroglobulin determinations, I ${ }^{131}$ scans and I ${ }^{131}$ uptakes after triodothyronine withdrawal in patients with thyroid cancer. J. Clin. Endoc. Met., 1981; 53:1199-1206.

Endereço para correspondência:

Dr. Aluízio Rodrigues

Rua Smith Vasconcelos, 81

22241-160 — Rio de Janeiro-RJ 